\title{
PEMBERDAYAAN MASYARAKAT DAN PENGEMBANGAN KAMPUNG TEMATIK DI KELURAHAN PEDALANGAN MELALUI PENGEMBANGAN BATIK DENGAN TEKNIK ECOPRINT
}

\author{
${ }^{1}$ Saptianing, ${ }^{2}$ Andi Setiawan, ${ }^{3}$ Rifah Dwi Astuti dan ${ }^{4}$ Rara Ririn Budi U \\ 1,2,3,4 Jurusan Administrasi Bisnis Politeknik Negeri Semarang \\ Jl Prof. H. Soedarto, S.H., Tembalang, Semarang 50275 \\ E-mail: saptianing@yahoo.com
}

\begin{abstract}
Batik is not only known domestically, but is also an attraction for foreign people. One of the things that can be done by batik artisans is to improve the quality of batik, the diversity of patterns / motifs of batik that is interesting, unique, and high value so that consumer demand is not decreased. For this reason, the innovation of batik motifs, the strategy of making batik and the quality of materials are considered very important for the development of Indonesian batik motifs, so that they can continue to attract the attention of consumers. Lately, one of the batik motifs that is very much in demand from both domestic and foreign consumers is ecoprint batik. Batik motifs produced with ecoprint techniques. Currently the problem of these Batik UKM is the number of ecoprint batik orders that cannot be fulfilled due to the limitations of Batik UKM in Pedalangan Village, this is because many batik craftsmen have not used the ecoprint technique. Ecoprint technique is the art of processing cloth by giving features using natural resources such as leaves, flowers, stems and other natural dyes. Semarang State Polytechnic as a Higher Education Institution, should have taken part in the provision of enhancing the ability of the craftsmen in empowering batik with ecoprint techniques. Another outcome of this dedication in addition to providing material and empowering the process of making batik is the institutional strengthening that is integrated between the community, government and Polines.
\end{abstract}

Key Words: Empowerment, Batik ecoprint

\begin{abstract}
Abstrak
Batik tidak hanya dikenal di dalam negeri, tetapi juga menjadi daya tarik masyarakat luar negeri, Salah satu hal yang dapat dilakukan oleh para perajin batik adalah meningkatkan kualitas batik, keaneka ragaman corak /motif batik yang menarik, unik, serta bernilai tinggi agar permintaan konsumen tidak menurun. Untuk itu, inovasi motif batik, strategi pembuatan batik serta kualitas bahan dinilai sangat penting demi berkembangnya motif batik Indonesia, sehingga dapat tetap menarik perhatian konsumen. Belakangan ini salah satu motif membatik yang sangat banyak permintaan dari konsumen baik dari dalam negeri maupun luar negeri adalah batik ecoprint. Motif batik yang dihasilkan dengan teknik ecoprint. Saat ini yang menjadi kendala dari UKM batik tersebut adalah banyaknya pesanan batik ecoprint yang belum bisa dipenuhi karena keterbatasan UKM Batik Kelurahan Pedalangan, hal ini dikarenakan pengrajin batik banyak yang belum menggunakan Teknik ecoprint. Teknik ecoprint merupakan seni mengolah kain dengan memberi corak menggunakan sumber kekayaan alam seperti dedaunan, bunga, batang dan pewarna alam lainnya. Politeknik Negeri Semarang sebagai Lembaga Perguruan Tinggi, sudah semestinya
\end{abstract}


ikut ambil bagian dalam bentuk pemberian peningkatan kemampuan para pengrajin tersebut dalam pemberdayaan membatik dengan teknik ecoprint. Luaran lain dari pengabdian ini selain pemberian materi dan bantuan pemberdayaan proses membuat batik adalah penguatan kelembagaan yang terpadu antara masyarakat, pemerintah dan Polines.

Key Words: Pemberdayaan, Batik ecoprint

\section{A. PENDAHULUAN}

Batik tidak hanya dikenal di dalam negeri, tetapi juga menjadi daya tarik masyarakat luar negeri. Potensi batik Indonesia dikhawatirkan terkikis tanpa adanya upaya pelestarian dan pengembangan yang dilakukan oleh perajin batik Indonesia. Eksistensi batik Indonesia sangat ditunjang oleh perkembangan batik itu sendiri baik dari segi keunikan motif, pewarnaan, makna simbolis yang terkandung maupun harga batik di pasaran.

Salah satu hal yang dapat dilakukan oleh para perajin batik Indonesia adalah meningkatkan kualitas batik, keaneka ragaman corak / motif batik agar batik yang mereka produksi dapat tetap menarik perhatian konsumen. Pengrajin batik harus membuat corak/motif yang menarik, unik, serta bernilai tinggi agar permintaan konsumen tidak menurun. Untuk itu, inovasi motif batik, serta strategi pembuatan batik serta kualitas dari bahan maupun pewarnaan serta pemasaran dinilai sangat penting demi berkembangnya motif batik Indonesia.

Mengingat bahwa jenis batik sangat dipengaruhi oleh selera konsumen, maka perkembangan industri batik di Indonesia setidaknya harus selalu memahami perkembangan pasar baik menyangkut penampilan, corak pewarnaan dan kegunaannya yang disesuaikan dengan permintaan dan kebutuhan pasar baik dalam maupun luar negeri. Keberadaan batik saat ini tidak lagi digolongkan sebagai mode yang ketinggalan zaman tetapi mampu mengikuti trend mode masa kini karena semakin beragamnya motif dan desain yang ada. Untuk itulah banyak sekali bermunculan pengrajin batik yang baru yang ada di Indonesia, tak terkecuali pengrajin batik yang ada di Kelurahan Pedalangan Kecamatan Banyumanik Semarang.

Pengrajin batik yang ada dikelurahan Pedalangan Banyumanik Semarang muncul ketika pemerintah menggerakkan batik sebagai budaya bangsa, sehingga banyak sekali daerahdaerah yang dilatih batik secara gratis lewat kelurahan- kelurahan. Demikian halnya dengan 
warga kelurahan Pedalangan banyak diantara warga yang belajar membatik, hingga akhirnya jumlah mereka yang menekuni batik berjumlah kurang lebih 40 orang. Ibu Lurah Pedalangan Yaitu Ibu Nanik Kusrini SH, sebagai penggerak kader PKK merasa senang melihat ketekunan para ibu-ibu ketika mereka belajar membatik, sehingga ibu Nanik berusaha untuk mengembangkan mereka untuk menjadi pengusaha batik yang lebih professional. Maka setiap ada even dari Deperindak, dari Perguruan Tinggi, yang ingin mengembangkan mereka diterima dengan tangan terbuka. Hingga akhirnya para pengrajin batik tersebut dibagi menjadi 2 kelompok yaitu . Kelompok I diketuai oleh Ibu Olief yang sudah memiliki outlet bernama Kinanti Wastra Batik Semarang dan kelompok II diketuai oleh Ibu Sulistia Rahayu yang sudah mempunyai outlet bernama outlet Kampung Hasta Karya. Diharapkan dari kedua kelompok tersebut akan menjadi ikon desa Pedalangan sebagai kampung batik seperti halnya desa-desa lainya di Kampung desa Tematik yang ada di Kota Semarang. kampung Tematik merupakan program pemerintah daerah yang berusaha menggali dan mengembangkan unggulan masing-masing wilayah, agar wilayah tersebut mempunyai keunggulan pada bidang tertentu atau menghasilkan produk tertentu. Diharapkan dengan adanya keunggulan-keunggulan yang dimiliki pada wilayah tersebut maka diharapkan dapat mengurangi kemiskinan.

Untuk mengembangkan usaha tersebut dan melestarikan budaya bangsa tentunya tidak mudah. Ibu Lurah sering mengajak beberapa perguruan tinggi untuk ikut membantu dalam pengembangan tersebut yang salah satunya Jurusan Administrasi Bisnis Politeknik Negeri Semarang. Dari pengabdian Masyarakat yang dilakukan sebelumnya tentang pewarnaan alami dan pembuatan batik kombinasi banyak permintaan dari para pengrajin batik untuk diadakan pelatihan membatik dengan Teknik ecoprint dikarenakan banyak permintaan dari konsumen. Saat ini yang menjadi kendala dari UKM batik tersebut adalah memenuhi selera konsumen akan kebutuhan batik Ecoprint.

Teknik ecoprint merupakan seni mengolah kain dengan memberi corak menggunakan sumber kekayaan alam seperti dedaunan, bunga, batang dan pewarna alam lainnya.Ecoprint memiliki beberapa Teknik pengolahan berbeda, salah satunya adalah Teknik steam atau kukus yang merupakan Teknik pengukusan kain yang memiliki pola daun yang sudah ditata sebelumnya. Untuk itulah Jurusan Administrasi Bisnis mencoba untuk membantu mereka dalam mengatasi permasalahan mereka. Bantuan yang ada berupa peralatan batik dan pelatihan membatik dengan Teknik ecoprint sehingga bisa memberikan nilai jual . 
Diharapkan dengan bantuan yang diberikan maka Kelurahan Pedalangan akan menjadi kampung tematik yang dibanggakan oleh warganya maupun masyarakat pada umumnya.

Banyaknya pesanan kain batik Ecoprint yang belum bisa dipenuhi karena keterbatasan UKM Batik Kelurahan Pedalangan, hal ini dikarenakan pengrajin batik banyak yang belum menggunakan Teknik Ecoprint. Kondisi dan situasi ini bisa menjadi masukan bagi Tim Pengabdian Kepada Masyarakat Jurusan Administrasi Bisnis (AB) Politeknik Negeri Semarang (Polines) untuk bersama dengan UKM Batik di Wilayah Pedalangan untuk mengatasi permasalahan yang ada Tim Pengabdian dan UKM Batik di wilayah pedalangan yang diketuai oleh Ibu Sulistia Rahayu yang sudah mempunyai outlet kampung Hasta karya yang beranggotakan 20 orang, sepakat untuk merencanakan program pelatihan bertujuan untuk meningkatkan kompetensi mereka dalam kaitannya pembuatan batik dengan Teknik Ecoprint.

\section{B. METODE PELAKSANAAN}

Dalam rangka menunjang pemecahan permasalahan yang dihadapi oleh UKM Batik Kelurahan Pedalangan maka kegiatan ini menawarkan pelatihan membatik dengan Teknik ecoprint guna menunjang usahanya, maka rangkain kegiatan yang ditawarkan adalah sebagai berikut: 1). Pemberian materi tentang membatik dengan teknik ecoprint; 2). Pemberian pelatihan membatik dengan teknik ecoprint dengan metode steam; dan 3). Pemberian bantuan bahan-bahan dan peralatan membatik dengan Teknik ecoprint. Kegiatan pengabdian masyarakat dilaksanakan melalui 3 (tiga tahapan) yang merupakan satu kesatuan rangkaian kegiatan, yakni: A). Fase 1: Kegiatan pendahuluan (introduction), Tahapan atau fase ini sudah dilakukan berdasarkan pengabdian sebelumnya yaitu dari masukan dan permintaan dari anggota pelatihan untuk diberikan pelatihan membatik dengan Teknik ecoprint.dengan melakukan observasi obyek yang akan di pilih, yaitu 1). Pengenalan obyek masyarakat; 2). Pendataan potensi permasalahan dan solusi; 3). Identifikasi masalah yang ada; 4). Identifikasi masalah metode pemecahanan masalah; dan 4). Identifikasi masalah manajemen. B). Fase 2: Kegiatan penilaian (assessment), Fase kedua, rangkaian kegiatan yang akan dilakukan ada yaitu; 1). Penilaian kelayakan tempat; 2). Menghitung kebutuhan alat; 3). Evaluasi kompetensi SDM dan kinerja SDM; dan 4). Penilaian manajemen organisasi UKM Batik Kelurahan Pedalangan. C). Fase 3: Pelaksanaan (implemetasi) rencana yaitu 1). Pengadaan bahan-bahan dan peralatan membatik dengan Teknik ecoprint; 2). Penyusunan materi pelatihan untuk pengolahan bahan dan membatik dengan Teknik ecoprint; 3). Pelatihan 
membatik dengan Teknik ecoprint; dan 4). Melakukan monitoring dan evaluasi tentang keberhasilan program

\section{HASIL DAN PEMBAHASAN}

Peserta adalah anggota Kelompok Usaha Bersama Batik Kanfer Kelurahan Pedalangan yang tergabung dalam pengerak lingkungan masyarakat, berjumlah 15 peserta. Adapun pelaksanaan program pengabdian masyarakat Di Kelurahan Pedalangan diuraikan sebagi berikut:

\section{Pendahuluan}

Kegiatan program pengabdian kepada masyarakat diawali dengan pengisian daftar hadir peserta yang dikelola oleh Ibu Dra.Rara Ririn Budi Utami M.Si sekaligus sebagai pembawa acara. Sedangkan Bapak Andi Setiawan SE, MM membantu mendokumentasikan seluruh aktivitas pada pelaksanaan Pengabdian kepada masyarakat Jurusan Administrasi Bisnis Polines pelaksanaan program diawali dengan pembukaan yang disampaikan oleh Ibu Dra. Saptianing, MM selaku wakil dari Tim Pengabdian Program Jurusan Administrasi Bisnis Polines. Sambutan berikutnya dari Ketua KUB Batik Kanfer Kelurahan Pedalangan yaitu Ibu SSulistia Rahayu

\section{Pemberian Teknologi Tepat Guna}

Proses berikutnya setelah sambutan-sambutan adalah penyerahan alat teknologi tepat guna pelestarian batik Berikut ini jenis dan jumlah alat yang diserahkan dari Tim Pengabdian masyarakat Jurusan Administrasi Bisnis Polines kepada KUB Batik Kanfer Kelurahan Pedalangan:

\begin{tabular}{|l|l|c|l|}
\hline \multicolumn{1}{|c|}{ Jenis } & Jumlah & \multicolumn{1}{c|}{ Manfaat } \\
\hline Bahan membatik & Bantuan & $1 \mathrm{set}$ & Pembuatan batik Ecoprint \\
\hline Peralatan membatik & Bantuan & $1 \mathrm{set}$ & Pembuatan batik Ecoprint \\
\hline $\begin{array}{l}\text { Perlengkapan } \\
\text { membatik }\end{array}$ & Bantuan & $15 \mathrm{set}$ & Pembuatan batik Ecoprint \\
\hline
\end{tabular}

Jenis dan jumlah peralatan tersebut di atas diserahkan Ibu Dra Saptianing MM kepada Ibu Setia Rahayu yang dalam pelaksanaan acara serah terima disaksikan oleh tim pengabdian masyarakat dan para peserta pengabdian. Penyerahan alat dijadwalkan lebih 
awal, dimaksudkan agar alat dapat langsung dapat dipergunakan pada saat sesi pelatihan dan praktek membatik dengan teknik ecoprint dengan metode steam Setelah acara serah terima alat tersebut, dilanjutkan penandatangan berita acara serah terima alat di mana, pihak pertama Jurusan Administrasi Bisnis Polines diwakili oleh Ibu Dra. Saptianing, MM dan pihak kedua diwakili oleh Ibu Sulistia Rahayu ketua Kelompok Usaha Bersama batik Kanfer Kelurahan Pedalangan Semarang.

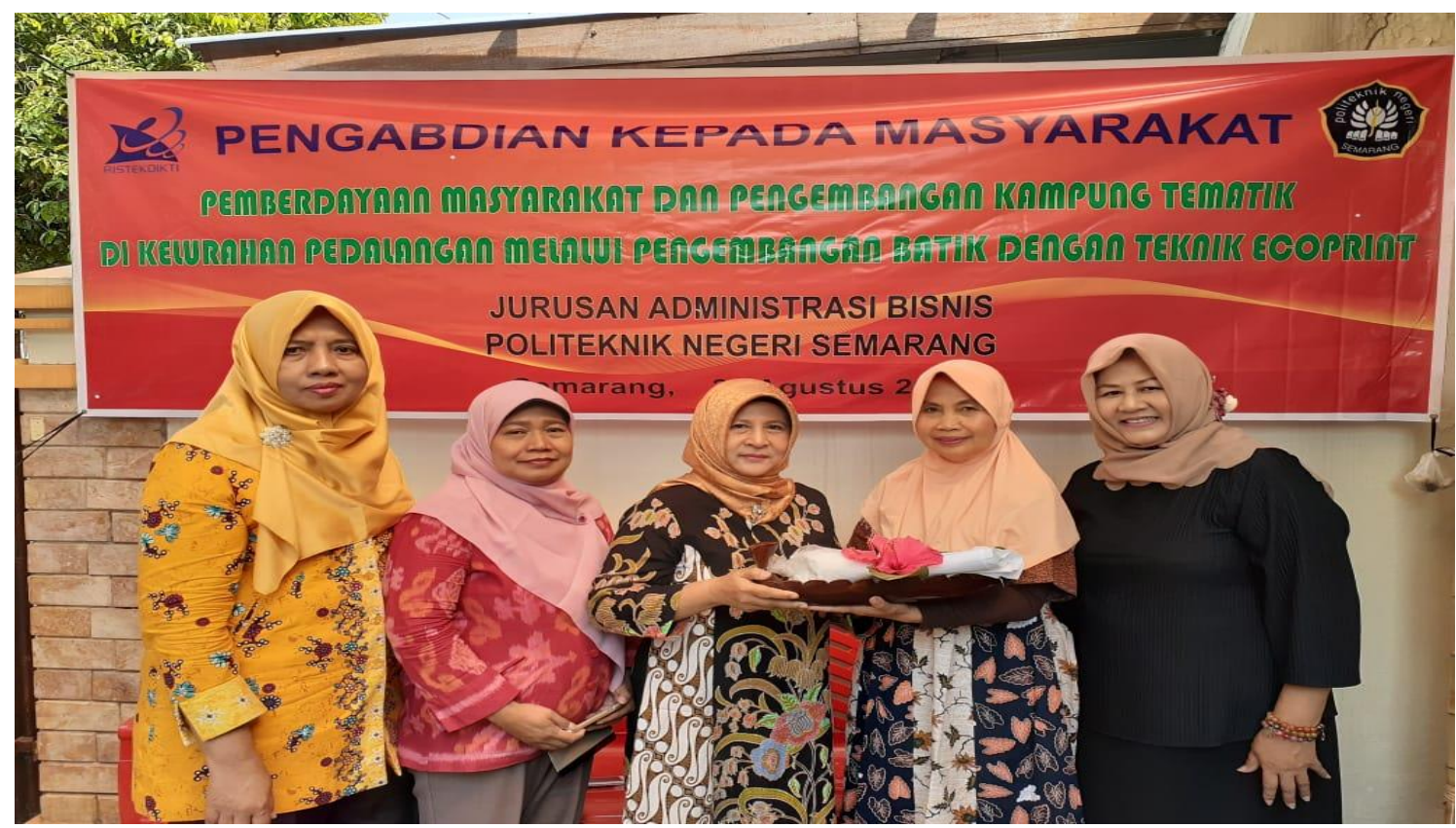

Gambar 1 Serah Terima Bantuan Dari Tim Pengabdian kepada Perwakilan Peserta Pelatihan

\section{Penyampaian Materi Pelatihan membatik dengan teknik ecoprint}

Penyampain materi pelatihan membatik oleh Ibu Sulistia Rahayu dan mbak Pintya Dwanita Ayu Pratesti. Bentuk penyampain materi pelatihan melalui ceramah tentang cara pengolahan kain agar bisa di batik dengan teknik ecoprint, bahan2 alami berupa daun2, bunga, kulit bawang bombai, kayu secang dan bahan2 lain yang bisa digunakan untuk bahan membatik.

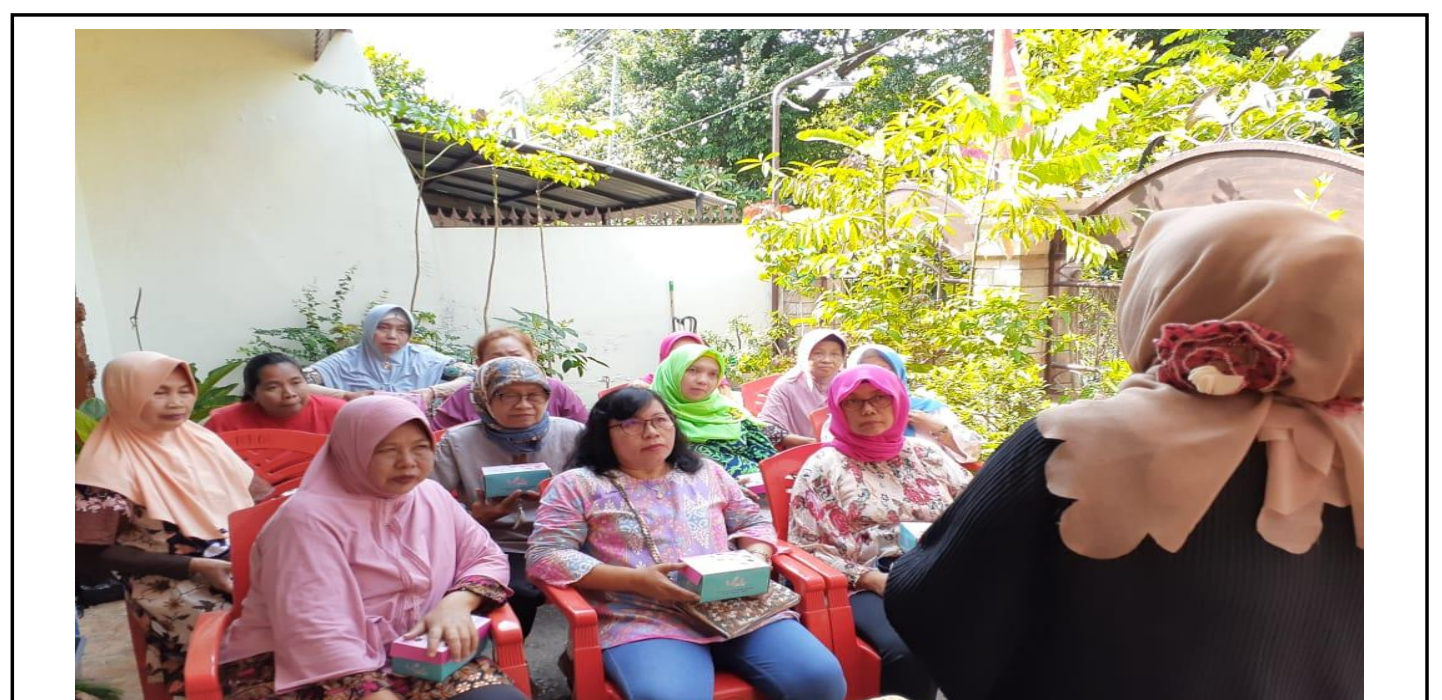




\section{Gambar 2 Penyampaian Materi oleh Narasumber}

Tujuan dari penyajian materi ini adalah penguatan pengetahuan akan batik dan pengembangan membatik dengan teknik ecoprint. Selesai penyajian materi, selanjutnya praktek treatment daun dengan mencelupkan daun pada air hangat sampai tercium aroma daun kemudian daun dicelupkan pada larutan tanjung lalu ditiriskan. Untuk treatment kain katun dengan merendam ke dalam pewarna ke dalam pewarna alam hingga meresap dan merata ke dalam kain lalu didiamkan. Proses selanjutnya dengan menata daun yang sudah di treatment di atas kain sesuai pola yang diinginkan.kemudian digulung dan dikukus selama 2 jam, setelah dikukus dibuka dan didinginkan setelah kering difiksasi menggunakan larutan tawas.
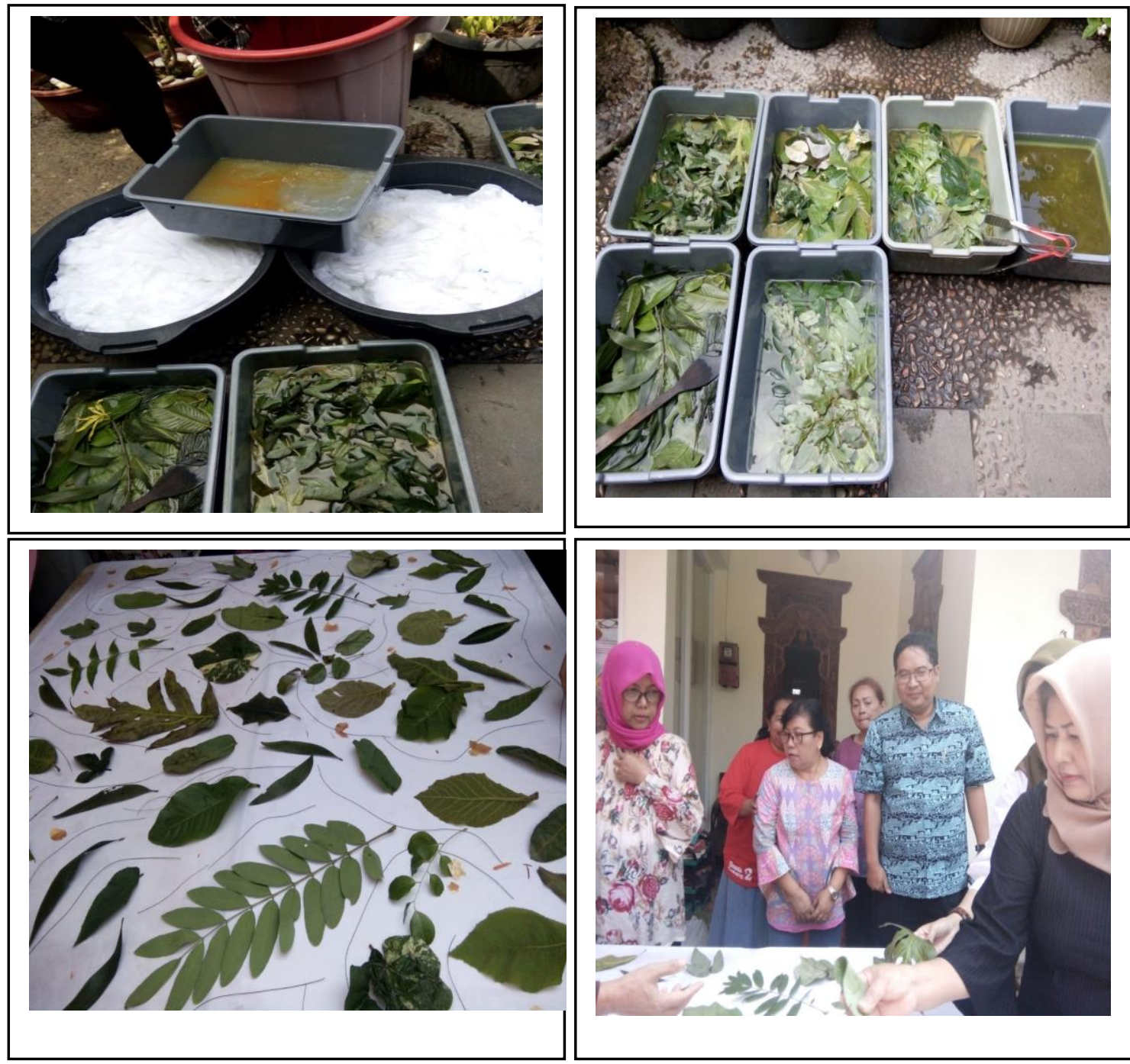


\section{Gambar 3 Tahapan Praktik Teknik Ecoprint}

Proses praktek berjalan baik, pelestarian dan pengembangan batik memperlihatkan bagaimana teknik ecoprint dengan metode steam (kukus). Selain Ibu setia Rahayu dan mbak Pintya dari tim pengabdian dalam hal ini Ibu Dra.Saptianing, MM,Bapak Andi Setiawan SE, MM, Ibu Rifah Dwi Astuti, SE., MM serta Ibu Ririn BU, Msi nampak aktif membantu. Pada saat praktek komunikasi nampak lebih baik, karena peserta lebih mempunyai gambaran tentang membatik dengan teknik ecoprint.

\section{KESIMPULAN}

Hasil dari kegiatan Pengabdian Kepada Masyarakat yang berjudul Pemberdayaan Masyarakat dan Pengembangan Kampung Tematik Di Kelurahan Pedalangan Melalui Pengembangan Batik dengan teknik Ecoprint, adalah sebagai berikut: 1). Peserta adalah anggota UKM Batik di lingkungan Kelurahan Pedalangan Semarang; 2). Para peserta terlihat sangat antusias dan penuh perhatian serta aktif bertanya sampai dengan acara pelatihan selesai; 3). Bantuan peralatan yang diberikan untuk pengembangan usaha berupa : Bahan membatik 1 set, Peralatan membatik 1 set, perlengkapan membatik 15 set; 4). Diharapkan dengan bantuan tersebut mereka bisa meningkatkan kemampuan pelestarian batik. dan pengembangan batik dengan teknologi dengan teknik ecoprint.
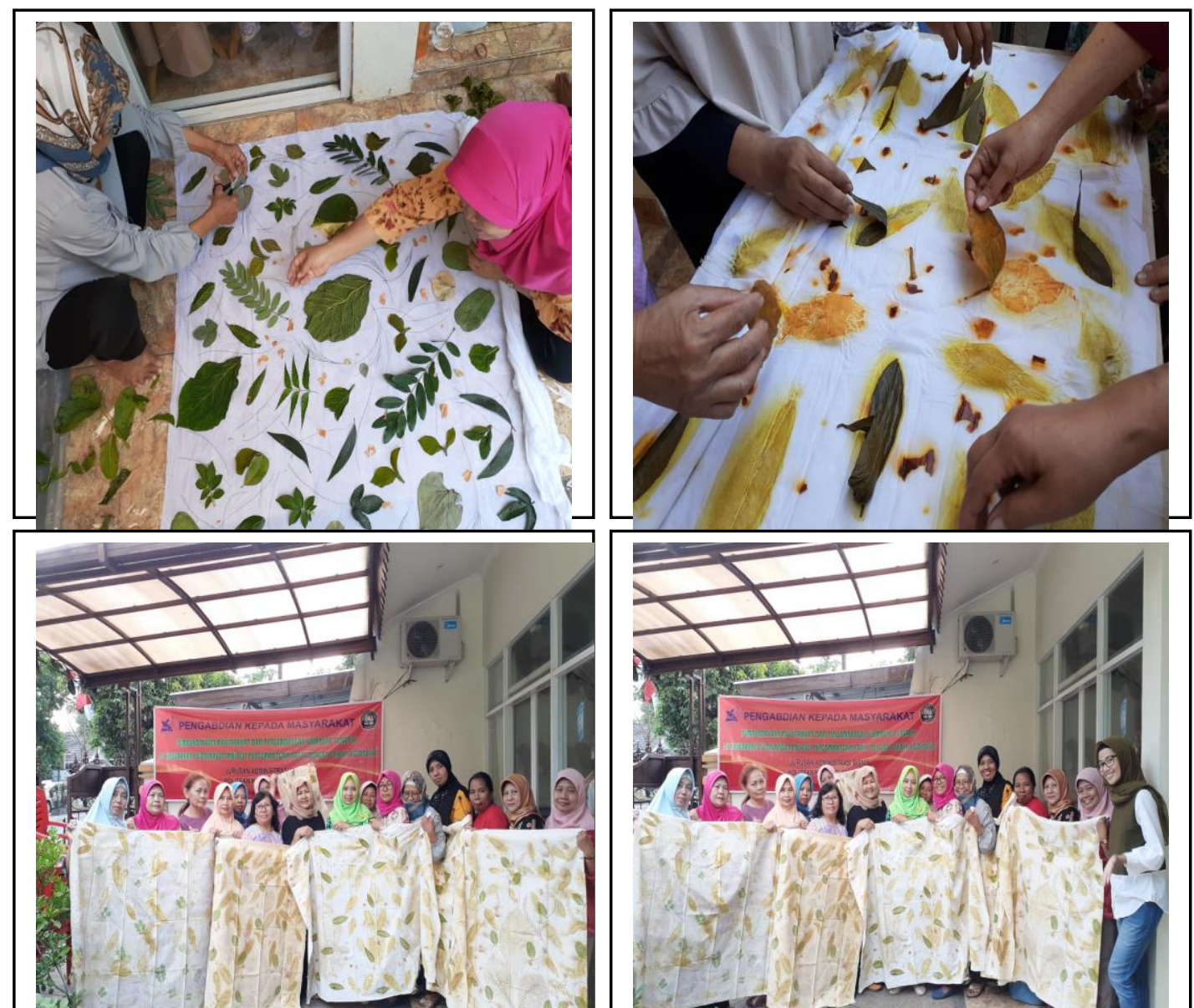


\section{Gambar 4 Tim Pengabdian, Narasumber dan Seluruh Peserta serta Karya Hasil Pelatihan Ecoprint}

\section{E. SARAN}

Rangkaian pelaksanaan tidak ada kendala yang berarti sama sekali,Para peserta terlihat sangat antusias dan penuh perhatian serta aktif bertanya sampai dengan acara pelatihan selesai. Pengrajin UKM Batik Kelurahan Pedalangan mendapat pengetahuan bagaimana meningkatkan kualitas pengrajin terutama dalam kemampuannya membuat batik dengan teknik ecoprint. Keberadaan teknologi dan praktek pelestarian batik dan pengembangan batik dengan teknik ecoprint menjadi salah satu alternatip solusi yang tepat mewujudkan kampung tematik.

Beberapa saran dan permohonan program yang diperoleh dari kuesioner yang disebar oleh panitia kepada para peserta didapati beberapa saran dan permohonan program diantaranya Mengupayakan program pelatihan lanjutan tentang medium ecoprint atau Botanical ecoprint. Penguatan melalui bantuan pelatihan manajemen pemasaran menjadi lebih baik di masa depan.

Adapun rencana tahapan program berikutnya: 1). Melanjutkan peningkatan kompetensi dalam pelestarian batik lanjutan dengan target untuk wilayah RW yang belum mendapatkan pada program 2019. Tahapan yang akan dilaksanakan pada periode berikutnya adalah target RW yang belum mendapatkan pada periode 2019; dan 2). Mengupayakan program pelatihan lanjutan tentang medium ecoprint atau Botanical ecoprint. Penguatan melalui bantuan pelatihan manajemen pemasaran menjadi lebih baik di masa depan. 


\section{DAFTAR PUSTAKA}

Andreas Kuckertz (2015) Management: Entrepreneurial Marketing”, Springer Gabler

Hisrich, Robert D., Michael P. Peters, And Dean A. Shepherd ,(2017) “,Entrepreneurship”,Tenth Edition McGraw-Hill Education

Phan, Phillip H., Sarfraz A Mian., and Wadid Lamine (2016) Technology Entrepreneurship And Business Incubation Theory Practice Lessons Learned, Imperial College Press

Rif'ah Dwi Astuti (2015)"Cara membatik dan mewarnani", Hibah Seni Dikti

Scarborough, Norman M. and Jeffrey R. Cornwall (2016) Essentials of Entrepreneurship and Small Business Management, Eighth Edition Pearson Education Limited

Rudiyansyah ( November 2018) “Batik Cantik Teknik Ecoprint” 